\title{
CREEP RUPTURE OF WATER-ABSORBED GREEN COMPOSITE
}

\author{
HIDEAKI KATOGI \& KENICHI TAKEMURA \\ Department of Mechanical Engineering, Kanagawa University, Japan
}

\begin{abstract}
The creep rupture properties of a water-absorbed green composite were examined and assessed for long-term safety. Plain woven jute fiber cloth was used as a reinforcement and a poly-lactic acid (PLA) resin sheet was used as a matrix. A water-absorption test of this green composite was conducted at room temperature, for 24 hours: The water absorption rate at 24 hours was $8 \%$. Quasistatic tensile tests of water-absorbed green composites were conducted at a crosshead speed $0.1,1.0$ and $10 \mathrm{~mm} / \mathrm{min}$; as well as on non-water-treated control material. Tensile creep tests of the nonwater-treated and $8 \%$ water-absorbed green composites were conducted. The environmental temperature was room temperature. The maximum test time was 100 hours. We found that Young's modulus and tensile strength of the non-water-treated and the $8 \%$ water-absorbed green composite increased with an increase in the strain rates. Young's modulus and tensile strength of the $8 \%$ waterabsorbed green composite were lower than those of the non-water-absorbed green composite, under all strain rates. Creep rupture strengths of the non-water-absorbed and the $8 \%$ water-absorbed green composites decreased with an increase of loading time. The creep rupture life of the $8 \%$ waterabsorbed green composite was lower than that of the non-water absorbed green composite. Generally, the glass transition temperature of PLA resin was decreased by water absorption; therefore, the creep rupture property of the green composite studied was mainly affected, due to a decrease of the viscoelasticity of the matrix by water absorption.
\end{abstract}

Keywords: creep rupture strength, creep rupture life, green composite, jute, natural fiber, polylactic acid, resin, strain, tensile strength, water absorption

\section{INTRODUCTION}

Recently, use of a green composite of natural fiber and biodegradable resin was forced [1][3]. The Toyota Boushoku Co., Ltd. produced automotive door trim using the green composite [4]. In addition, natural fiber was used as a reinforcement of the green composite, as a frame for cycling [5]. These green composites will be used as structural materials; so are many published papers about the mechanical properties of the green composite [6]-[11].

Ren et al. [12] reported on the tensile property of a green composite using unidirectional flax sliver. Tensile strength of the green composite using unidirectional flax sliver was found similar to that of aluminum. Katogi et al. [13] reported on the fatigue properties of unidirectional jute spun yarn, a reinforced green composite. The fatigue strength at 1 million cycles of the green composite was similar to that of glass-fiber-reinforced plastic.

Some companies are producing ultra-electric vehicles. Green composite will be able to be applied as a structural material for the ultra-electric vehicle; however, the creep property of green composite should be investigated for long-term safety.

Alvarez et al. [14] reported about the effect of fiber volume fraction on creep behavior of sisal-fiber-reinforced green composite under a nitrogen atmosphere. The creep compliance of green composite decreased with an increase of the fiber volume fraction. Takemura et al. [15] reported on the effect of silane treatment on the tensile creep property of green composite. When the maximum test time was 100 hours, the tensile creep strain of green composite using 5\% silane-treated jute fiber decreased to $30 \%$ lower than that of green composite using non-silane-treated jute fiber. 
As structural materials, the green composite will be used under rain and moisture environments. For the application of structural material, there are many papers about the mechanical properties of water-absorbed green composite [16], [17]; but there are few papers about creep rupture strength and the life of water-absorbed green composite. This study examined the creep rupture property of water-absorbed green composite for longterm safety.

\section{SPECIMENS}

The polylactic acid (PLA) resin sheet (Ecodear 250-1B01CA, Toray Co., Ltd.) was used as a matrix. Plain woven jute fiber cloth knitting jute spun yarn was used as reinforcement. Fig. 1 shows plain woven jute fiber cloth knitting jute spun yarn. For fabrication of green composite, the molding method was the vacuum-compression molding method. The molding temperature was $190^{\circ} \mathrm{C}$, the molding pressure was $1.7 \mathrm{MPa}$, and the holding time was $10 \mathrm{~min}$. After that, the mold was cooled to room temperature.

The water absorption rate of green composite at 24 hours was $8 \%$, when green composite had been immersed in distilled water at room temperature. Fiber volume fractions of the non-absorbed and $8 \%$ water-absorbed green composite were $42 \%$. Fig. 2 shows a schematic drawing of the specimen for the quasi-static tensile and creep tests. Specimen sizes were $200 \mathrm{~mm}$ long, $10 \mathrm{~mm}$ wide and $1.0 \mathrm{~mm}$ thick.

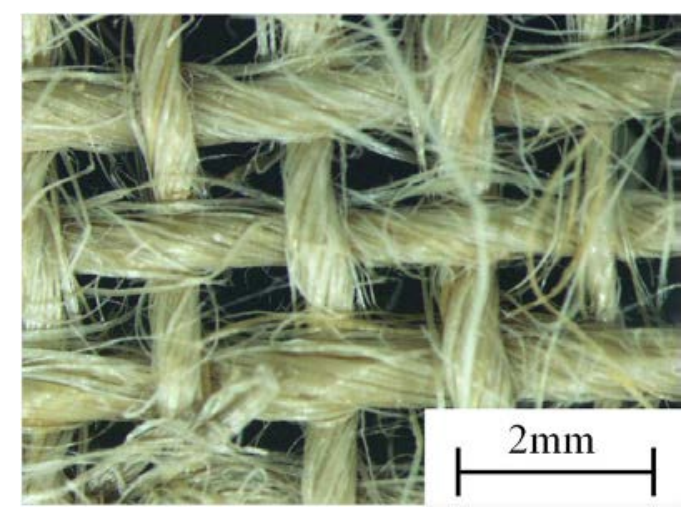

Figure 1: Plain woven jute fiber cloth.

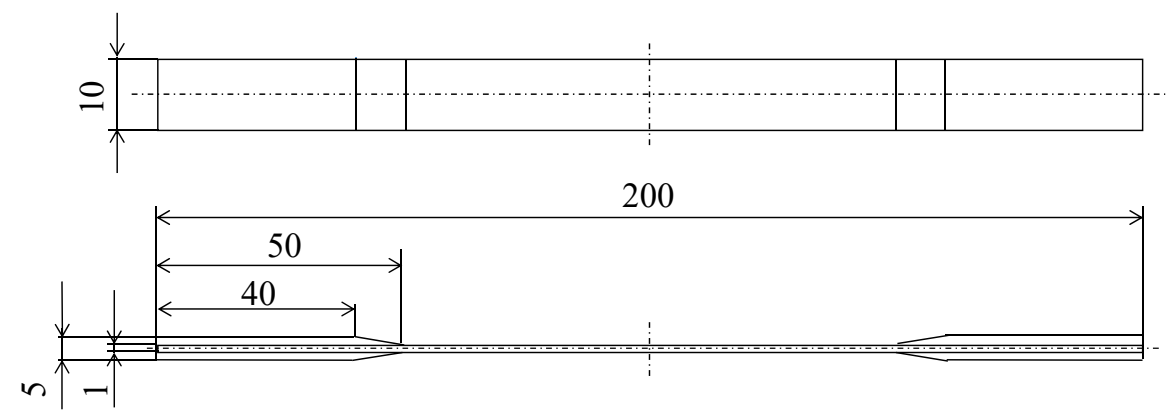

Figure 2: Schematic drawing of specimen sample for the quasi-static tensile and creep tests. 


\section{TESTING METHODS}

\subsection{Quasi-static tensile test}

Quasi-static tensile tests of 8\% water-absorbed green composites and non-water-absorbed controls were conducted based on the Japanese Industrial Standard (JIS) K 7164. The Tensilon RTG-1250A (A \& D Co., Ltd.) was used as a tensile testing machine; at crosshead speeds of $0.1,1.0$, and $10 \mathrm{~mm} / \mathrm{min}$ (strain rate: $3.4 \times 10^{-5} \mathrm{~s}^{-1}-3.4 \times 10^{-3} \mathrm{~s}^{-1}$ ); and gauge length of $25 \mathrm{~mm}$. Environmental temperature was room temperature. We tested five specimens.

\subsection{Tensile creep test}

Tensile creep test of $8 \%$ water-absorbed composite and non-water-absorbed controls were conducted, based on JIS K 7115. We used Creep tester 100LER (Toyo Seiki Seisaku-sho Co., Ltd.) as a testing machine. The maximum stress given was $50-90 \%$ of the tensile strength (crosshead speed: $1 \mathrm{~mm} / \mathrm{min}$ ), at room temperature, and the maximum test time was 100 hours. We observed the fracture morphologies of $8 \%$ water-absorbed green composites and their non-water-absorbed controls by optical microscope (SZY7, Olympus Co., Ltd.) after the tensile creep test.

\section{RESULTS AND DISCUSSION}

\subsection{Tensile property of green composite under strain rate}

Figs 3 and 4 show Young's modulus and tensile strength of 8\% water-absorbed green composites and non-water-absorbed controls under strain rates. Young's modulus and tensile strength of the $8 \%$ water-absorbed green composites and non-water-absorbed controls increased with an increase in strain rate. When the strain rate was $3.4 \times 10^{-3} \mathrm{~s}^{-1}$, we found that Young's modulus and the tensile strength of $8 \%$ water-absorbed green composite decreased by $32 \%$ and $38 \%$, respectively, as compared with the values obtained by non-water-absorbed green composite. Young's modulus and tensile strength of $8 \%$ water-absorbed green composite were lower than those of the non-water-absorbed green composite under all strain rates.

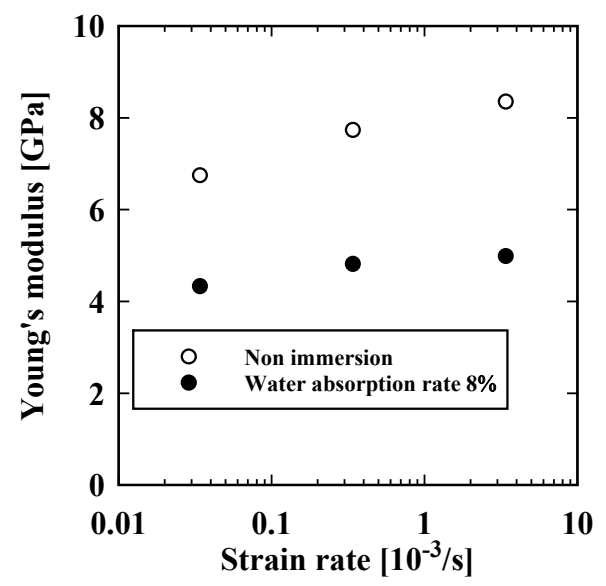

Figure 3: Young's modulus of water-absorbed green composites and non-absorbed controls under strain rates. 


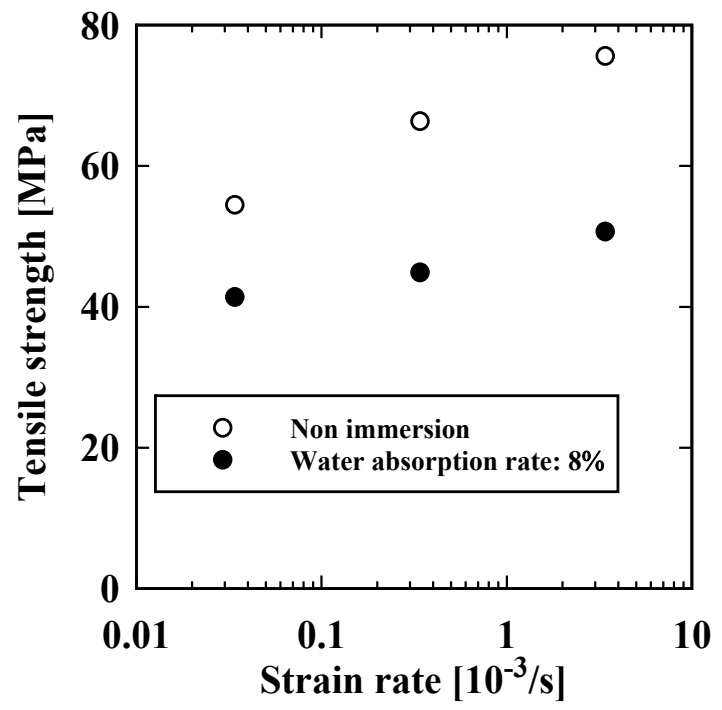

Figure 4: Tensile strengths of water-absorbed and non-water-absorbed green composites

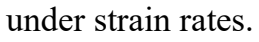

Generally, the glass transition temperature of the PLA resin was decreased by water absorption [18]; thus, the strain rate dependence of the green composite was mainly

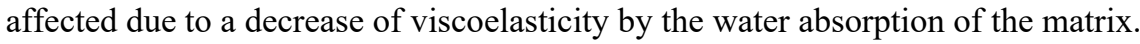

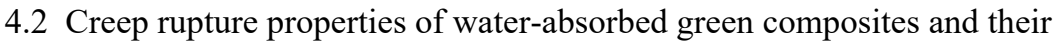

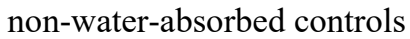

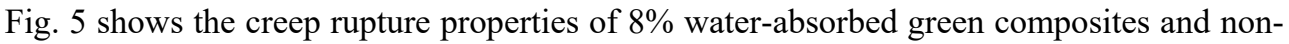

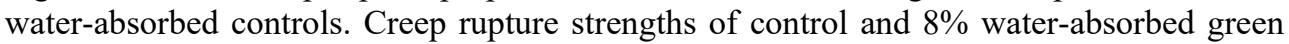

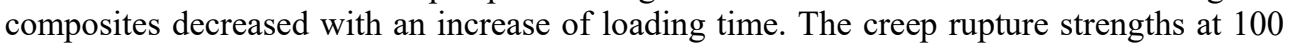
hours of control and $8 \%$ water-absorbed green composites were $33 \mathrm{MPa}$ and $23 \mathrm{MPa}$, respectively. The creep rupture life of $8 \%$ water-absorbed green composite was lower than that of non-water-absorbed green composite. When the maximum stress was $33 \mathrm{MPa}$, the creep rupture life of the non-water-absorbed green composite decreased $99 \%$, as compared with that of water-absorbed green composite. The creep rupture strength of the PLA resin decreased, with an increase of loading time [19]; thus, the creep rupture property of green

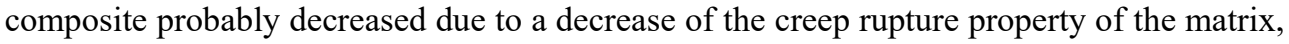

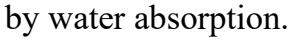

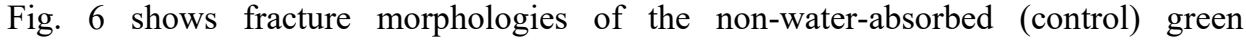
composites after tensile creep tests. The fracture morphology of this non-water-absorbed green composite became smooth. There were no different fracture morphologies for nonwater-absorbed green composites at maximum stresses of $60 \%$ and $80 \%$. Also, no large yarn pull-outs occurred in the fracture morphologies of non-water-absorbed green composites at maximum stresses of $60 \%$ and $80 \%$.

Fig. 7 shows fracture morphologies of $8 \%$ water-absorbed green composites after tensile creep tests. Fracture morphology of $8 \%$ water-absorbed green composite at a maximum 
stress of $80 \%$ became smooth, but we found a large yarn pull-out in the fracture morphology of $8 \%$ water-absorbed green composite at a maximum stress of $60 \%$. As mentioned above, the glass transition temperature of PLA resin was decreased by water absorption. The water probably penetrated into the interface between fiber and resin, when the green composite absorbed water. For these reasons, the yarn pull-out in the fracture morphology of green composite under a maximum stress of $60 \%$ probably occurred due to a decrease in interfacial adhesion between the fiber and resin; therefore, the creep rupture property of green composite was mainly affected due to a decrease in the viscoelasticity of the matrix by water absorption.

\section{CONCLUSIONS}

This study examined the creep rupture property of water-absorbed green composite for long-term safety. As a result, we concluded that: The tensile properties of non-absorbed and $8 \%$ water-absorbed green composites increased with an increase of the strain rate; the tensile properties of the $8 \%$ water-absorbed green composite were lower than those of nonwater-absorbed green composite, for all strain rates; the strain rate dependence of green composite decreased by water absorption. Creep rupture strengths of $8 \%$ water-absorbed green composites and non-water-adsorbed controls decreased with an increase of loading time. The creep rupture life of $8 \%$ water-absorbed green composite was lower than that of non-water absorbed green composite. Fracture morphologies of $8 \%$ water-absorbed green composite (as well as the non-water absorbed) at maximum stress of $60 \%$ and $80 \%$ became smooth, except for the $8 \%$ water-absorbed green composite at a maximum stress of $60 \%$; we found there was a large yarn pull out in the fracture morphology of $8 \%$ water-absorbed green composite at a maximum stress of $60 \%$. Therefore, the creep rupture property of green composite was mainly affected, due to a decrease in viscoelasticity of the matrix by water absorption.

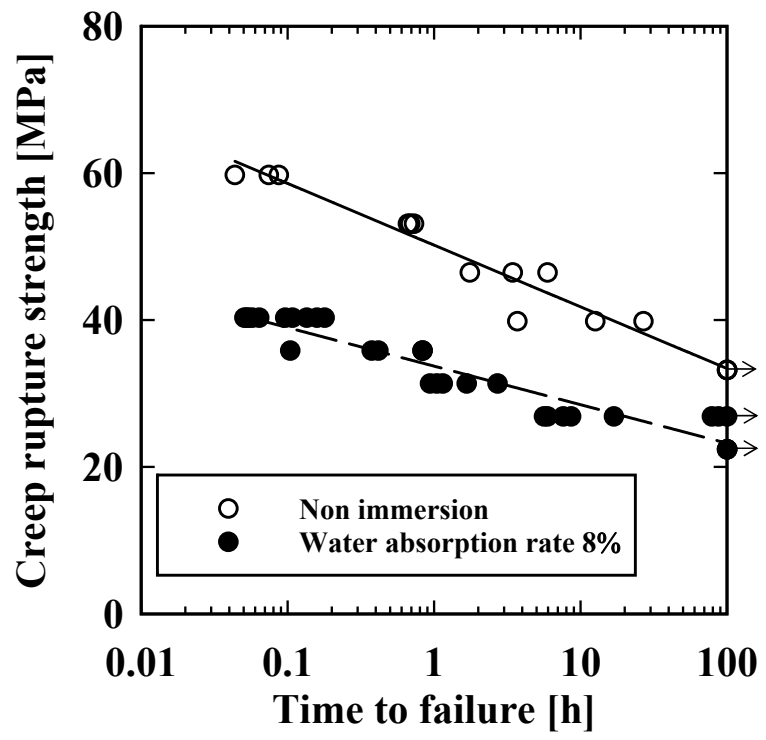

Figure 5: Creep rupture properties of $8 \%$ water-absorbed green composites and nonwater absorbed controls. 


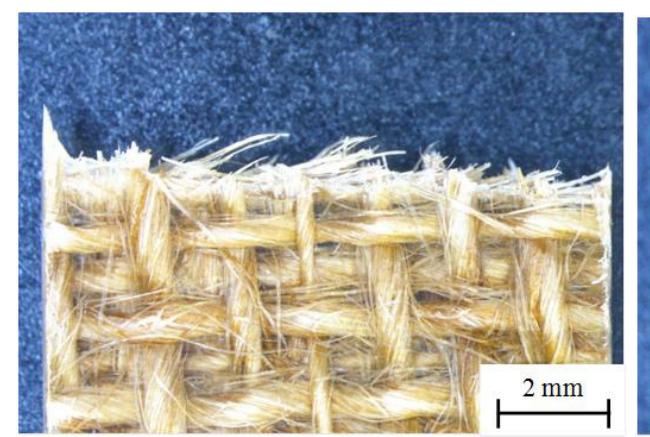

(a)

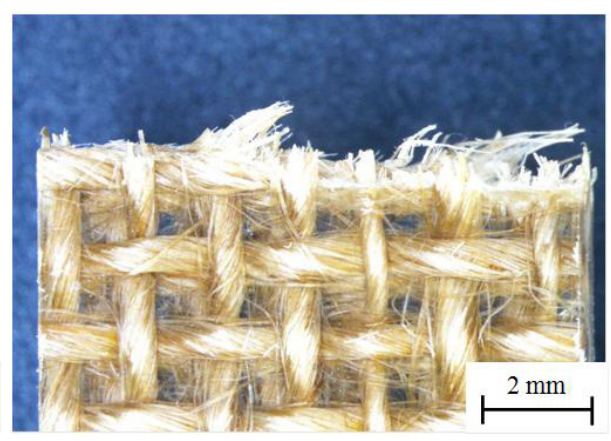

(b)

Figure 6: Fracture morphologies of the non-water-absorbed green composites after tensile creep tests. (a) Maximum stress $80 \%$; (b) Maximum stress $60 \%$.

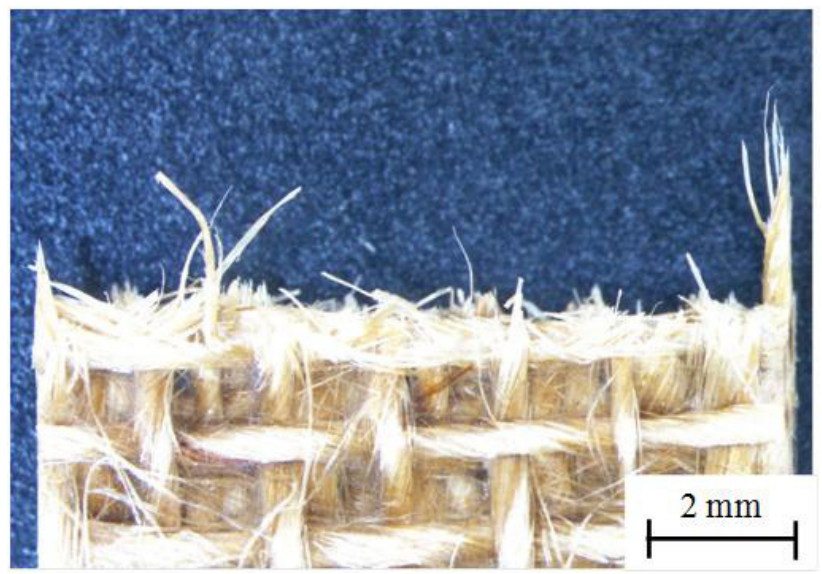

(a)

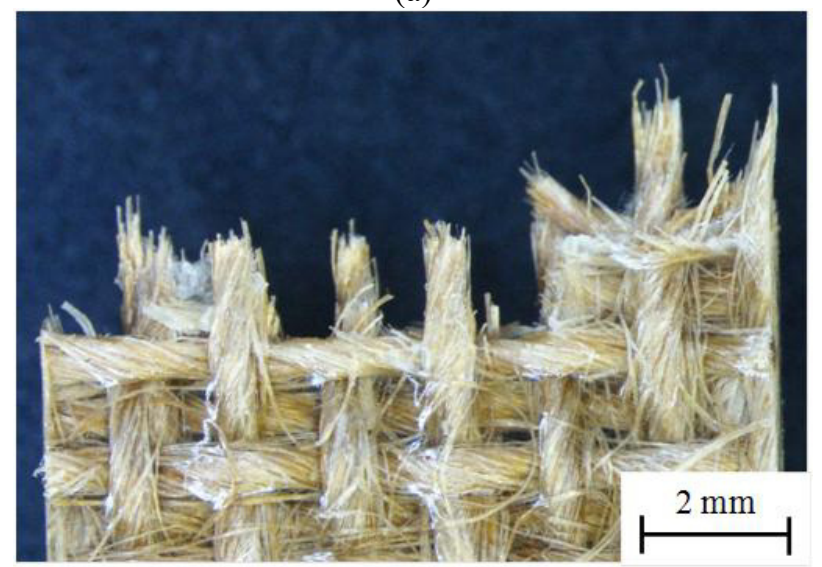

(b)

Figure 7: Fracture morphologies of $8 \%$ water-absorbed green composites after tensile creep tests. (a) Maximum stress $80 \%$; (b) Maximum stress $60 \%$. 


\section{REFERENCES}

[1] Koronis, G., Silva, A. \& Fontul, M., Green composites: a review of adequate materials for automotive application. Composites part B: engineering, 44, pp. 120127, 2013.

[2] Jayavani, S., Deka, H., Varghese, T.O. \& Nayak, S.K., Recent development and future trends in coir fiber-reinforced green polymer composites: review and evaluation. Polymer composites, 37, pp. 3296-3309, 2016.

[3] Wei, L. \& Mcdonald, A.G., A review on grafting of biofibers for biocomposites. Materials, 9, pp. 303-326, 2016.

[4] Toyota boshoku Co., Ltd, Online. http://www.toyota-boshoku.com/jp/products/fiberexterior/ door-trim/index.html.

[5] Guapa Co., Online. https://www.guapaco.com/pages/urban-one-black.

[6] Takagi, H. \& Asano, A., Effects of Processing Conditions on Flexural Properties of Cellulose Nanofiber Reinforced "Green" Composites. Composites part A: applied science and manufacturing, 39, pp. 685-689, 2008.

[7] Kobayashi, S., Damage behabior of hemp fiber reinforced poly (1-lactic acid) composites under fatigue loading. Journal of solid mechanics and materials engineering, 7, pp. 317-323, 2013.

[8] Kobayashi, S., Takeda, K. \& Nakamura, R., Processing and characterization of hemp fiber textile composites with micro-braiding technique. Composites part A: applied science and manufacturing, 59, pp. 1-8, 2014.

[9] Takagi, H, Nakagaito, A.N., Nishimura, K. \& Matsui, T., Mechanical characterisation of nanocellulose composites after strucural modification. WIT Transactions on the Built Environment, 166, pp. 335-341, 2016.

[10] Tanaka, K., Shiga, T. \& Katayama, T., Fabrication of hydroxyapatite/PLA composite nanofiber by electrospinning. WIT Transactions on the Built Environment, 166, pp. 371-379, 2016.

[11] Katogi, H., Takemura, K. \& Akiyama, M., Residual tesile property of pain woven jute fiber/poly(lactic acid) green composites during thermal cycling. Materials, 9, pp. 573-583, 2016.

[12] Ren, B., Mizue, T., Goda, K. \& Noda, J., Effects of fluctuation of fibre orientation on tensile properties of flax sliver-reinforced green composites. Composite structures, 94, pp. 3457-3464, 2012.

[13] Katogi, H., Shimamura, Y., Tohgo, K., Fujii, T. \& Takemura, K., Fatigue behavior of unidirectional jute spun yarn reinforced PLA. Advanced composite materials, 21, pp. 1-10, 2012.

[14] Alvarez, V.A., Kenny, J.M. \& Vazquez, A., Creep behavior of biocomposites based on sisal fiber reinforced cellulose derivatives/starch blends. Polymer composite, 25, pp. 280-288, 2004.

[15] Takemura, K., Takada, Y. \& Katogi, H., Effect of treatment using silane coupling agent on creep properties of jute fiber reinforced composites. WIT Transactions on the Built Environment, 124, pp. 417-424, 2012.

[16] Liu, W., Misra, M., Askeland, P., Drzal, L.T. \& Mohanty, A.K., 'Green' composites form soy based plastic and pineapple leaf fiber: fabrication and properties evaluation. Polymer, 46, pp. 2710-2721, 2005.

[17] Nam, T.H., Ogihara, S., Nakatani, H., Kobayashi, S. \& Song, J.I., Mechanical and thermal properties and water absorption of jute fiber reinforced poly (butylene succinate) biodegradable composite. Advanced composite materials, 21, pp. 241-258, 2012. 
[18] Takeyama, Y. \& Kawagoe, M., The dynamic viscoelasticity of molded PLA absorbing moisture and water. Proceedings of 46th Hokuriku Shin'etsu branch meeting, the japan society of mechanical engineering, pp. 11-12, 2009 (in Japanese).

[19] Ooi, K. \& Ohgi, J., Elongation behavior of poly lactic acid under creep loading. Proceeding of the 59th JSMS annual meetings, pp. 17-18, 2010 (in Japanese). 